\title{
Annealing effects on the migration of ion-implanted cadmium in glassy carbon
}

\author{
T.T. Hlatshwayo ${ }^{1}$, L.D. Sebitla ${ }^{1,2}$, E.G. Njoroge ${ }^{1}$, M. Mlambo ${ }^{1}$, J.B. Malherbe ${ }^{1}$, \\ ${ }^{1}$ Physics Department, University of Pretoria, Pretoria, South Africa \\ ${ }^{2}$ Physics Department, University of Botswana, Gaborone, Botswana
}

Corresponding author: thulani.hlatshwayo@up.ac.za

\begin{abstract}
The migration behavior of cadmium $(\mathrm{Cd})$ implanted into glassy carbon and the effects of annealing on radiation damage introduced by ion implantation were investigated. The glassy carbon substrates were implanted with $\mathrm{Cd}$ at a dose of $2 \times 10^{16}$ ions $/ \mathrm{cm}^{2}$ and energy of $360 \mathrm{keV}$. The implantation was performed at room temperature (RT), $430{ }^{\circ} \mathrm{C}$ and 600 ${ }^{\circ} \mathrm{C}$. The RT implanted samples were isochronally annealed in vacuum at 350, 500 and $600{ }^{\circ} \mathrm{C}$ for 1 hour and isothermally annealed at $350{ }^{\circ} \mathrm{C}$ up to 4 hours. The as-implanted and annealed samples were characterized by Raman spectroscopy and Rutherford backscattering spectrometry (RBS). Raman results revealed that implantation at room temperature amorphized the glassy carbon structure while high temperature implantations resulted in slightly less radiation damage. Isochronal annealing of the RT implanted samples resulted in some recrystallization as a function of increasing temperature. The original glassy carbon structure was not achieved at the highest annealing temperature of $600{ }^{\circ} \mathrm{C}$. Diffusion of $\mathrm{Cd}$ in glassy carbon was already taking place during implantation at $430{ }^{\circ} \mathrm{C}$. This diffusion of $\mathrm{Cd}$ was accompanied by significant loss from the surface during implantation at $600{ }^{\circ} \mathrm{C}$. Isochronal annealing of the room temperature implanted samples at $350{ }^{\circ} \mathrm{C}$ for 1 hour caused $\mathrm{Cd}$ to diffuse towards the bulk while isothermal annealing at 500 and $600{ }^{\circ} \mathrm{C}$ resulted in the migration of implanted $\mathrm{Cd}$ toward the surface accompanied by a loss of $\mathrm{Cd}$ from the surface. Isothermal annealing at $350{ }^{\circ} \mathrm{C}$ for 1 hour caused $\mathrm{Cd}$ to diffuse towards the bulk while for annealing time $>1$ hour $\mathrm{Cd}$ diffused towards the surface. These results were interpreted in terms of trapping and de-trapping of implanted $\mathrm{Cd}$ by radiation damage.
\end{abstract}

\section{Keywords:}

Glassy carbon, RBS, Ion Implantation, Diffusion, Raman 


\section{Introduction}

Glassy carbon (GC) is a micro-polycrystalline carbon material having combined glassy and ceramic properties with those of graphite. GC is a very stable material which does not transform to graphite at temperatures of up to $3000{ }^{\circ} \mathrm{C}$ [1]. Unlike graphite, glassy carbon has a fullerene-related microstructure [2]. It is an isotropic, continuous and nonporous material which is impervious [3]. GC exhibits attractive physical, chemical and mechanical properties. Its electrical resistivity is of the same order as that of regular carbon materials and its thermal conductivity is relatively high compared with that of common ceramic materials [4]. Its combined resistance to high temperature, corrosion and wear, together with low density, impermeability to gases and liquids makes glassy carbon more useful in many industrial applications such as vacuum evaporation sources, chemical containment, zone-refinement crucibles and more interestingly encapsulation of nuclear fuel elements [1], [4]. GC has also been proposed to be used as a protective layer on the graphite reactor core surface in molten salt breeder reactors [5].

Cadmium $(\mathrm{Cd})$ is used in reactor components such as control rods and neutron absorption shields, resulting in the formation of various radioactive isotopes including cadmium$113 \mathrm{~m} . \mathrm{Cd}$ is a fission product which forms metallic precipitates whose fission yield is very low (about $0.0002 \%$ ) [6]. This radioactive isotope is present in spent nuclear fuel and radioactive wastes associated with operating nuclear reactors and fuel reprocessing plants. Cadmium is a toxic heavy metal which can easily be dissolved by water and can damage the immune system, the central nervous system, and causes high blood pressure [7]. Therefore there is a need for proper containment of this fission product.

In the context of radioactive waste disposal related to the back end of the nuclear fuel cycle, we investigated whether glassy carbon can be a good nuclear waste containment material. For GC to be a good candidate for containment, it must be a good diffusion barrier for fission products such as $\mathrm{Cd}$ and its near-surface region structure must remain unchanged so that it retains its properties even under radiation conditions. In most of the above mentioned applications knowledge on $\mathrm{Cd}$ ion diffusion in GC is of crucial importance. 
Previous work on ion species implanted in GC include Be [8], Cs [9], Sr [10], Co [11] K [12], Na [13], Ti [14], N [15], W [16] but after extensive literature research no data for diffusion studies of Cd implanted in GC was found. Most of these studies investigated the improvement of mechanical properties of GC surface layer after ion implantation [17].

In this study, the effectiveness of glassy carbon as a good storage material was investigated. Cd ions were implanted into GC substrates to a fluence of $2 \times 10^{16}$ ions $/ \mathrm{cm}^{2}$ at room temperature and at higher temperatures (430 and $600{ }^{\circ} \mathrm{C}$ ). Post ion implantation annealing experiments (isothermal and isochronal) of RT implanted samples were conducted to investigate behaviour of $\mathrm{Cd}$ in $\mathrm{GC}$ at a temperature range of $350-600{ }^{\circ} \mathrm{C}$. The as-implanted samples and annealed samples were characterized by Raman spectroscopy and Rutherford backscattering spectrometry (RBS).

\section{Experimental}

The starting material was glassy carbon (Sigradur® G) which was mechanically polished to a mirror finish with a $1 \mu \mathrm{m}$ diamond solution. Cadmium ions with energy of $360 \mathrm{keV}$ were implanted into the polished glassy carbon surface, to fluence of $2 \times 10^{16}$ ions $/ \mathrm{cm}^{2}$ at room temperature (RT), 430 and $600{ }^{\circ} \mathrm{C}$. The flux was maintained at a rate of about $10^{13}$ $\mathrm{cm}^{-2} \mathrm{~s}^{-1}$ to minimize the increase in the substrate temperature. Some of the RT implanted samples were isochronally annealed in vacuum at temperatures of $350,500,600{ }^{\circ} \mathrm{C}$ for 1 hour and some were isothermally annealed at $350,500,600{ }^{\circ} \mathrm{C}$ from 1 hour to 4 hours in step of 1 hour.

The structure of the GC before implantation, the radiation damage retained after implantation and the effect of annealing were investigated by Raman spectroscopy. Raman spectra were recorded with a T64000 series II triple spectrometer system from HORIBA scientific, Jobin Yvon Technology, using the $514.3 \mathrm{~nm}$ laser line of a coherent

Innova ${ }^{\circledR} 70 \mathrm{C}$ series $\mathrm{Ar}^{+}$laser (spot size $\sim 2 \mu \mathrm{m}$ ) with a resolution of $2 \mathrm{~cm}^{-1}$ [18]. The samples were recorded in a backscattering configuration with an Olympus microscope attached to the instrument (using an LD 50x objective). The laser power was set at 1.5 $\mathrm{mW}$. An integrated triple spectrometer was used in the double subtractive mode to reject 
Rayleigh scattering and dispersed the light onto a liquid nitrogen cooled Symphony CCD detector.

The distributions of cadmium implanted in glassy carbon before and after annealing were monitored by using Rutherford backscattering spectrometry (RBS) at RT using $\mathrm{He}^{+}$ particles with energy of $1.6 \mathrm{MeV}$ at a backscattering angle of $165^{\circ}$. The beam current was kept between 10 and $15 \mathrm{nA}$ during the measurements. The Cd RBS profiles in energy channels were converted into depth profiles.

\section{Results and Discussion}

Raman spectra of Cadium (Cd) ions implanted in glassy carbon at RT, $430{ }^{\circ} \mathrm{C}$ and $600{ }^{\circ} \mathrm{C}$ compared with the un-implanted glassy carbon in the $800-1800 \mathrm{~cm}^{-1}$ range are shown in Fig. 1. The Raman spectrum of the un-implanted sample shows the glassy carbon characteristic peaks of the D (at about $1350 \mathrm{~cm}^{-1}$ ) and $\mathrm{G}$ (about $1590 \mathrm{~cm}^{-1}$ ) bands representing the $\mathrm{sp}^{3}$ and $\mathrm{sp}^{2}$ bonds, respectively. After ion bombardment at RT, these two peaks merged into a broad single peak due to randomly distributed $\mathrm{sp}^{3}$ and $\mathrm{sp}^{2}$ bonds, indicating the amount of radiation damage retained after implantation. The randomly distribution of $\mathrm{sp}^{3}$ and $\mathrm{sp}^{2}$ bonds is termed disordered amorphous carbon. This implies that the RT Cd ions implantation induced amorphization in the near surface region of GC which has been previously observed [19], [20]. Implantation at $430{ }^{\circ} \mathrm{C}$ resulted in broader D peak which became narrower after implantation at $600{ }^{\circ} \mathrm{C}$. This indicates reordering of $\mathrm{sp}^{3}$ bonds due high temperature implantations. The similar implantations $\left(430^{\circ} \mathrm{C}\right.$ and 600 ${ }^{\circ} \mathrm{C}$ ) also resulted into a shift of the G-peak from 1590 (of un-implanted GC) to 1564 and $1584 \mathrm{~cm}^{-1}$ respectively, indicating the recovery of radiation damage. These results indicate the presence of some $\mathrm{sp}^{3}$ and $\mathrm{sp}^{2}$ bonds after $\mathrm{Cd}$ implantation at these temperatures. The difference in the radiation damage retained after implantation with the same energy and fluence resulted in disordered amorphous carbon at room temperature and recrystallization of the GC due to to self-healing/annealing occurring at high temperature implantations [9], [20]. 


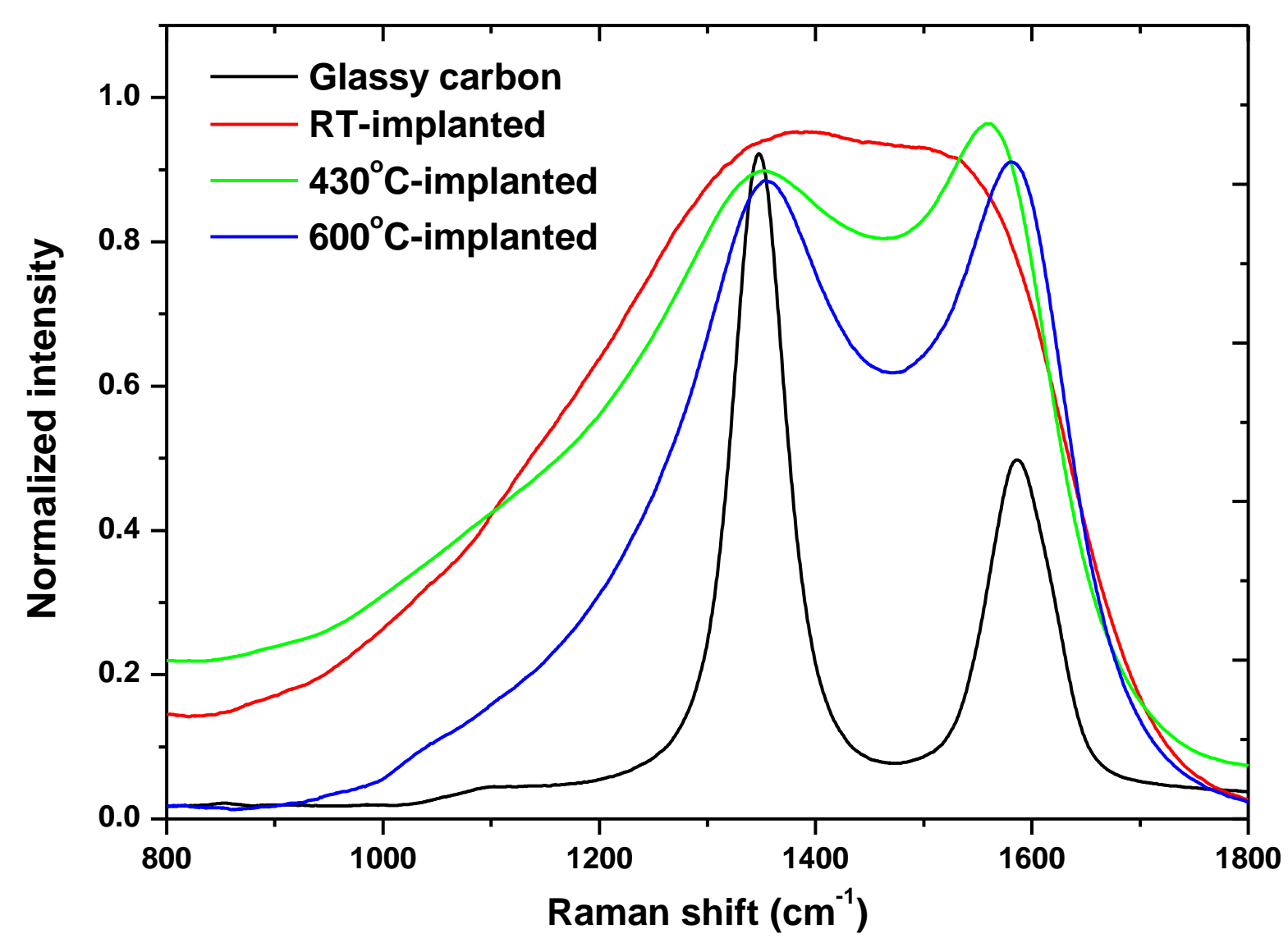

Figure 1: Raman spectra of cadmium implanted into glassy carbon at room temperature (RT), $430{ }^{\circ} \mathrm{C}$, and $600{ }^{\circ} \mathrm{C}$, the un-implanted glassy carbon spectrum is included for comparison.

The RBS spectra of glassy carbon implanted with Cd ions at RT, $430{ }^{\circ} \mathrm{C}$ and $600{ }^{\circ} \mathrm{C}$ are shown in Fig. 2, surface positions of $\mathrm{C}$ and $\mathrm{Cd}$ are indicated by the arrows. Room temperature implantation resulted in the almost Gaussian distribution of implanted $\mathrm{Cd}$. Implantation at $430{ }^{\circ} \mathrm{C}$ resulted in the broader profile that is skewed more towards the surface. This is due to Cd diffusion towards the GC surface during implantation at this temperature. More diffusion of $\mathrm{Cd}$ towards the surface accompanied by significant loss of $\mathrm{Cd}$ was observed after implantation at $600{ }^{\circ} \mathrm{C}$. The $\mathrm{Cd}$ peak has a high energy edge near its surface energy channel implying that the $\mathrm{Cd}$ atoms appeared at the $\mathrm{GC}$ surface. This is due to surface temperature effect and radiation-induced diffusion at the elevated implantation temperatures. What is also evident from these results (Fig. 2) is that very little Cd diffused into the bulk of glassy carbon. This signifies that the diffusion is due to the radiation damage in the glassy carbon. 


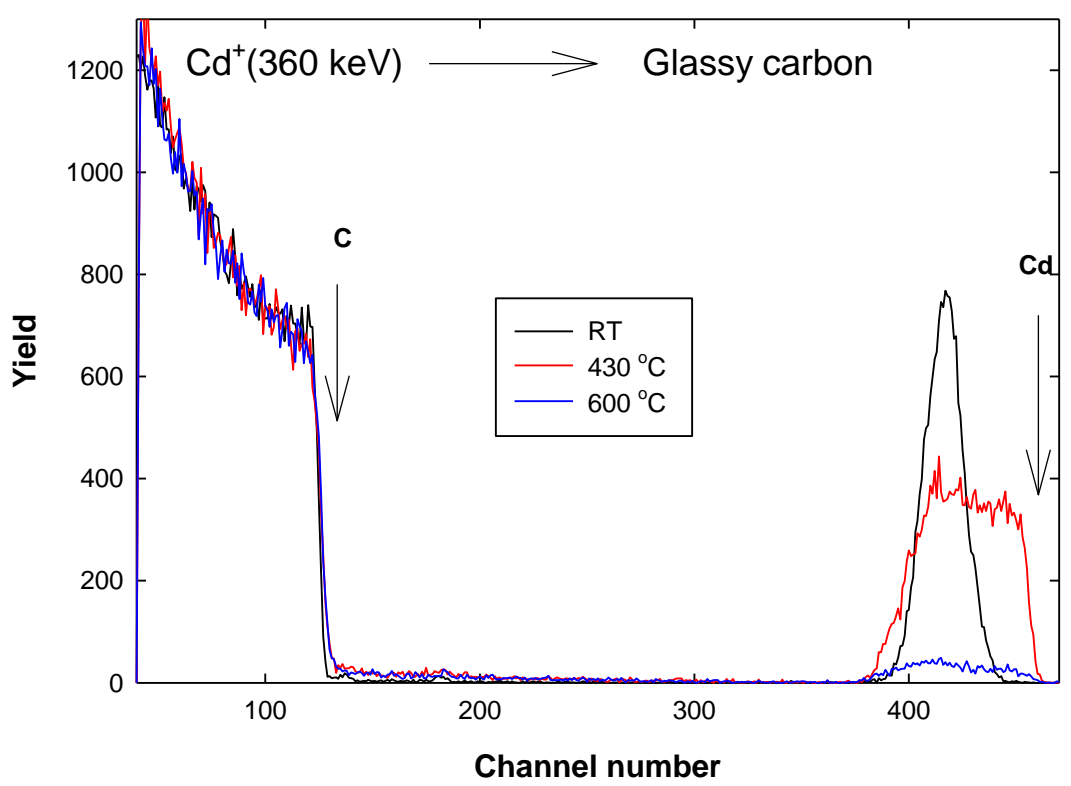

Figure 2: Rutherford backscattering spectroscopy (RBS) spectra of cadmium implanted into glassy carbon at room temperature $(\mathrm{RT}), 430{ }^{\circ} \mathrm{C}$, and $600{ }^{\circ} \mathrm{C}$.

Fig. 3 shows the Raman spectra of $\mathrm{Cd}$ implanted in glassy carbon at room temperature and annealed at different temperatures in-comparison with the un-implanted glassy carbon spectrum. Annealing different samples at 350,500 and $600{ }^{\circ} \mathrm{C}$ for 1 hour resulted in the reappearance of D and G Raman peaks; this is due to some recrystallization in the GC structure. The reappeared D peaks became broader with increasing annealing temperature; this was accompanied by slight decrease in peak intensities. These indicate recrystallization accompanied with clustering of $\mathrm{sp}^{2}$ [15]. The similar annealing also resulted in narrowing of the $G$ peak with negligible change in peak positions. The reappeared $G$ peak intensities were much higher than the $G$ peak intensity of the unimplanted GC indicating the strong recovery of the $\mathrm{sp}^{2}$ bonds. This suggests that recrystallization of pre-damaged GC does not yield to original structure of GC before implantation. 


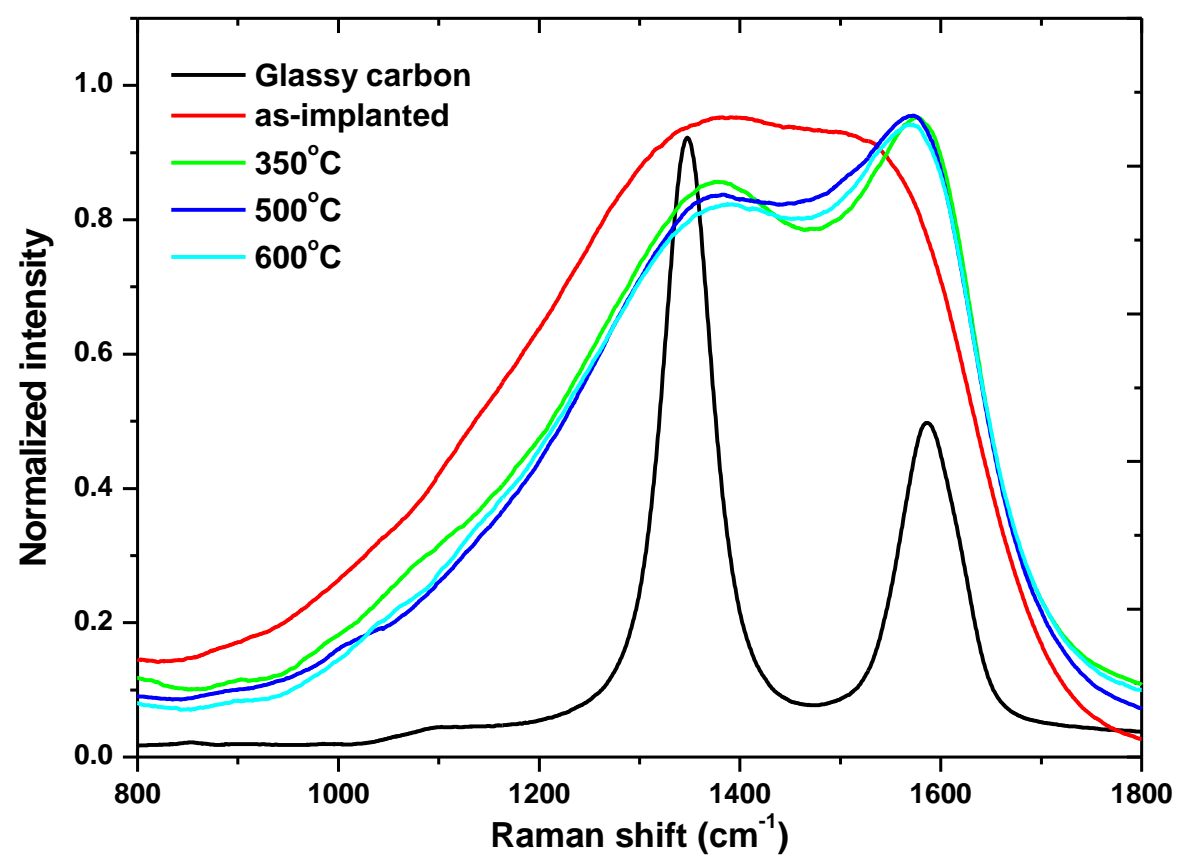

Figure 3: Raman spectra of Cd implanted into glassy carbon at room temperature after isochronal annealed at $350{ }^{\circ} \mathrm{C}, 500{ }^{\circ} \mathrm{C}$ and $600{ }^{\circ} \mathrm{C}$ for 1 hour, the as-implanted and the un implanted glassy carbon spectra are included for comparison.

Comparing these results with the as-implanted results, it is evident that recrystallization due annealing results to stronger recovery radiation damage than implantation at elevated temperatures. The more recrystallization to graphitic carbon was also confirmed by the decreasing $\mathrm{I}_{\mathrm{D}} / \mathrm{I}_{\mathrm{G}}$ ratio to $0.89,0879$, and 0.873 after annealing at 350,500 , and $600{ }^{\circ} \mathrm{C}$ respectively while an increase of the $\mathrm{I}_{\mathrm{D}} / \mathrm{I}_{\mathrm{G}}$ ratio to 0.92 and 0.96 after implantation at 430 and $600{ }^{\circ} \mathrm{C}$.

Fig. 4 shows the $\mathrm{Cd}$ depth profiles obtained after the isochronal annealing at $350{ }^{\circ} \mathrm{C}, 500$ ${ }^{\circ} \mathrm{C}$ and $600{ }^{\circ} \mathrm{C}$ for 1 hour compared with the as-implanted depth profile. Their square of the full width at half maximum (FWHM) and the calculated Cd retained ratios are shown in Fig. 5 as a function of annealing temperature. The FWHMs were obtained by fitting the Gaussian function to the $\mathrm{Cd}$ depth profiles. The retained ratios were taken as the ratio of the area of $\mathrm{Cd}$ counts after annealing to that of the as-implanted sample. 


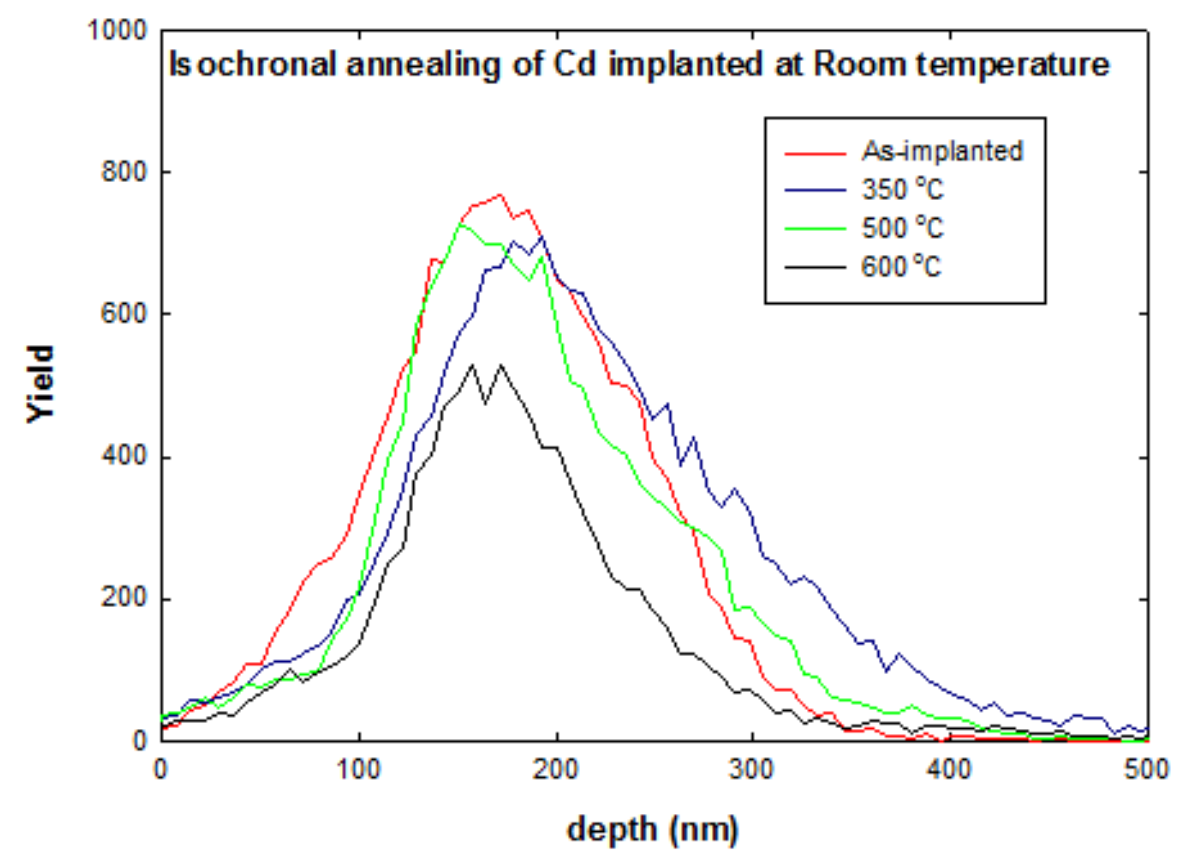

Figure 4: Depth profiles of $\mathrm{Cd}$ implanted at room temperature after isochronal annealing at $350{ }^{\circ} \mathrm{C}, 500$ ${ }^{\circ} \mathrm{C}$, and $600{ }^{\circ} \mathrm{C}$ for 1 hour compared to as-implanted depth profiles.

Annealing at $350{ }^{\circ} \mathrm{C}$ caused some movement of implanted $\mathrm{Cd}$ towards the bulk resulting in the increase in the FWHM of Cd profile that is skewed towards the bulk as observed in Fig.4 and Fig 5(a). No Cd was lost after annealing at this temperature as seen in Fig.5(b). This broadening towards the bulk indicates diffusion of $\mathrm{Cd}$ towards the bulk. Annealing at $500{ }^{\circ} \mathrm{C}$ and $600{ }^{\circ} \mathrm{C}$ resulted in the movement of $\mathrm{Cd}$ towards the surface accompanied by narrowing of the profiles due loss of $\mathrm{Cd}$ at the surface. These results indicate the diffusion of $\mathrm{Cd}$ towards the surface. The $\mathrm{Cd}$ profiles are narrow due to the loss at the surface after annealing at $500{ }^{\circ} \mathrm{C}$ and $600{ }^{\circ} \mathrm{C}$ (Fig.5 (b)). Based on these results, the migration of implanted $\mathrm{Cd}$ in glassy carbon occurs via two independent processes. Firstly, $\mathrm{Cd}$ diffuses into the bulk at low temperature i.e. $350{ }^{\circ} \mathrm{C}$. Secondly, $\mathrm{Cd}$ diffuses towards the surface at higher temperature $\left(500\right.$ and $\left.600{ }^{\circ} \mathrm{C}\right)$ where it is accompanied by the loss of implanted Cd. 

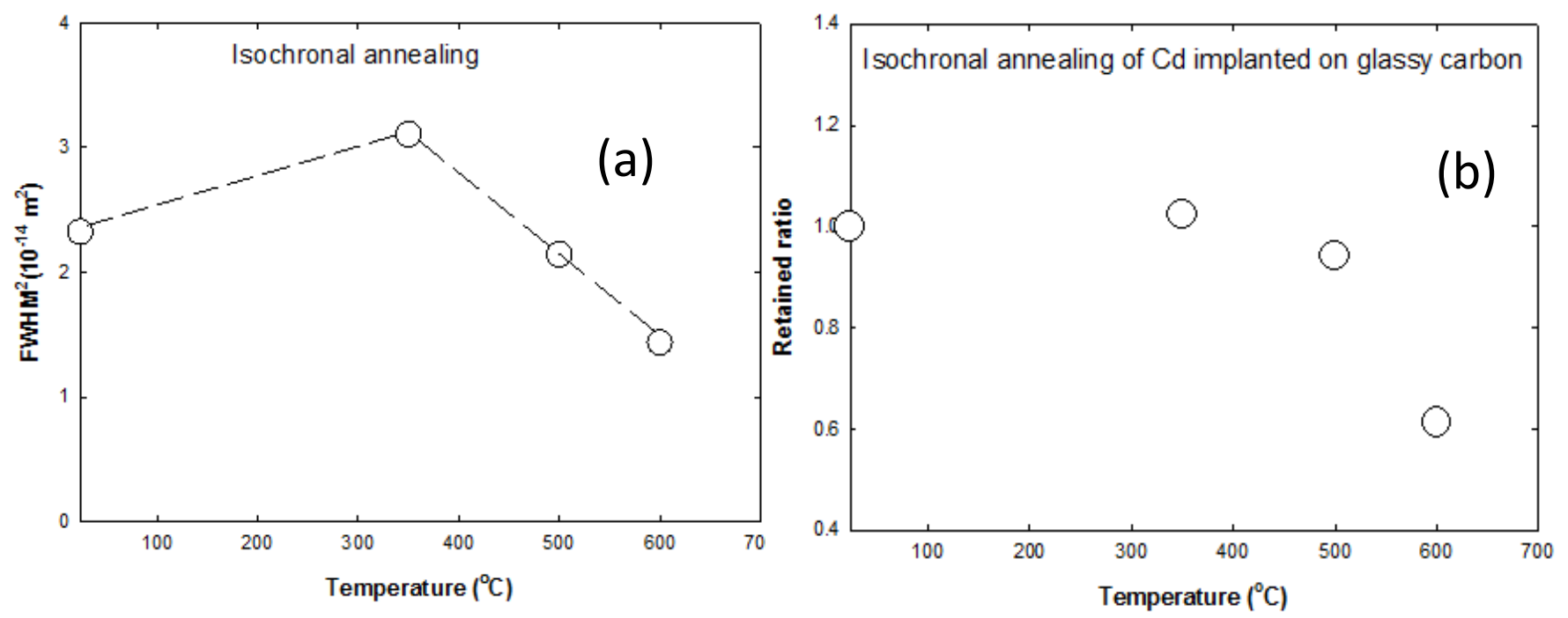

Figure 5: The Square of the full width at half maximums (FWHMs) (a), Cd retained ratio (b) as a function of annealing temperature.

Fig. 6 shows the as-implanted $\mathrm{Cd}$ depth profile together with simulated radiation damage from SRIM 2010 using glassy carbon density of $1.43 \mathrm{~g} / \mathrm{cm}^{3}$ [21]. The ion fluence was converted into displacements per atom $(d p a)$ using:

$$
d p a=\frac{\frac{v_{a c}}{\text { ion } \AA^{0}} \times 10^{8}}{\rho_{C}\left(\text { atomscm }^{-3}\right)} \times \varphi\left(\text { ionscm }^{-2}\right)
$$

where $\varphi$ is the ion fluence, $\rho_{c}$ is the theoretical density of glassy carbon $\left(1.43 \mathrm{gcm}^{-3}\right)$ and $\frac{v_{a c}}{0}$ is the vacancy per ion ratio from SRIM 2010 [21]. ion $\mathrm{A}$ 


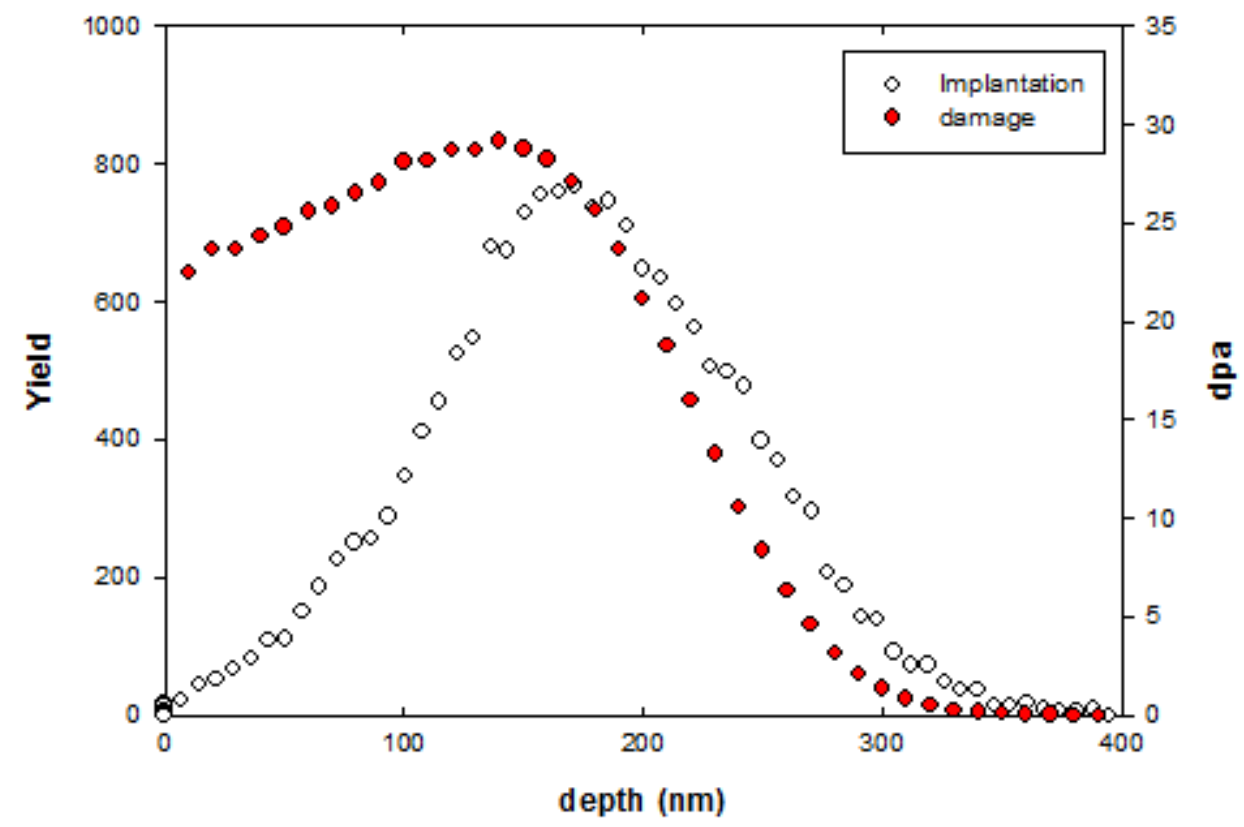

Figure 6: Depth profile of Cd implanted into glassy carbon at room temperature and radiation damage in dpa from SRIM 2010 [21].

The results in Fig. 6 show that some of the implanted $\mathrm{Cd}$ is embedded in a region with high radiation damage and other in a low radiation damage region. These results and the results in Fig. 4 show that diffusion of Cd towards the bulk at $350{ }^{\circ} \mathrm{C}$ is occurring in the less defective/damaged region. This diffusion in the less damaged region might be explained in terms of trapping and de-trapping of implanted $\mathrm{Cd}$ in the radiation damage region (in the more defective/damaged region). Therefore, annealing at $350{ }^{\circ} \mathrm{C}$ only causes $\mathrm{Cd}$ to diffuse towards the bulk where the radiation damage is minimum. At the same time, the $\mathrm{Cd}$ situated in the region with highest radiation damage is still trapped and cannot diffuse until the radiation damage is annealed out to allow diffusion. Annealing at 500 and $600{ }^{\circ} \mathrm{C}$ caused fast annealing of the defects/damage thus allowing diffusion towards the surface resulting in the loss of implanted $\mathrm{Cd}$ from the surface. These findings are in agreement with the as-implanted results in Fig.1 and Fig.2 which revealed more radiation damage retained at lower temperature than higher temperature thus more $\mathrm{Cd}$ implants were trapped at lower implantation temperature. The slight migration of $\mathrm{Cd}$ towards the bulk at higher implantation temperatures occurs due to less radiation damage (not enough to trap the implants) on the implanted and un-implanted interface. 
The depth profiles of $\mathrm{Cd}$ implanted into glassy carbon at room temperature after isothermal annealing at $350{ }^{\circ} \mathrm{C}$ up to 4 hours are shown in Fig. 7. Similar to the isochronal annealing in Fig. 4, annealing for 1 hour caused $\mathrm{Cd}$ to diffuse towards the bulk. However, further annealing at same temperature for 2 hours caused $\mathrm{Cd}$ to diffuse towards the surface. This diffusion towards the surface was more pronounce after 4 hours of annealing. These results are in agreement with our initial speculation of trapping and de-trapping by radiation damage of implanted $\mathrm{Cd}$ in the high radiation damage region. During 1 hour of annealing radiation damage are enough to completely hinder $\mathrm{Cd}$ from diffusing towards the surface, after 1 hour of annealing some of defects are annealed out which allows $\mathrm{Cd}$ to diffuse towards the surface. The process repeats itself with longer annealing time which results in more $\mathrm{Cd}$ diffusing towards the surface.

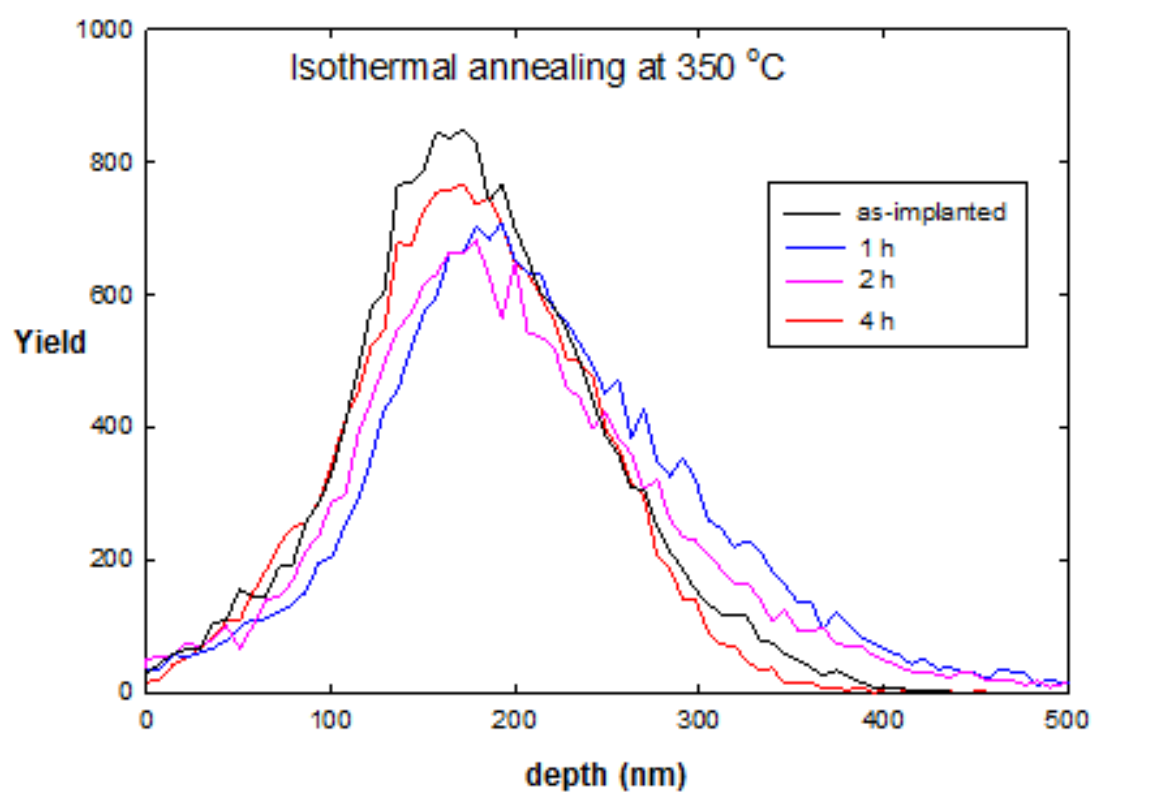

Figure 7: Depth profiles of Cd implanted at room temperature after isothermal annealing at $350{ }^{\circ} \mathrm{C}$ up to 4 hours compared to the as-implanted depth profiles.

The diffusion coefficient of $\mathrm{Cd}$ in less defective/damage glassy carbon was estimated by comparing the full width at fall maximum (FWHM) of the as-implanted Cd depth profile to the FWHM of the sample annealed at $350{ }^{\circ} \mathrm{C}$ for 1 hour [22]:

$$
W^{2}(t)=W^{2}(0)+4 D t \ln (2)
$$


The value of $7.82 \times 10^{-19} \mathrm{~m}^{2} \mathrm{~s}^{-1}$ was obtained. No $\mathrm{Cd}$ diffusion in GC data has been reported in literature. Therefore, we could not compare our diffusion coefficient with any reported results.

In summary these results shows that $\mathrm{Cd}$ does not diffuse in non-defective glassy carbon and high defective glassy carbon. It only diffuses in the less defective glassy carbon. These are essential results if one considers glassy carbon a radioactive containment as was the purpose of this study.

\section{Conclusions}

The effect of annealing on Cd implanted on GC and its migration behaviour was investigated using RBS and Raman spectroscopy. $\mathrm{Cd}^{+}$of $360 \mathrm{keV}$ were implanted at RT, 430 and $600{ }^{\circ} \mathrm{C}$ to a fluence of $2 \times 10^{16} \mathrm{~cm}^{-2}$. The RT implanted samples were isochronally annealed at 350,500 and $600{ }^{\circ} \mathrm{C}$ for 1 hour and isothermally annealed at $350{ }^{\circ} \mathrm{C}$ up to 4 hours.

RT implantation resulted into disordered amorphous carbon while high temperature implantations caused some recrystallization of the GC due to to self-healing/annealing. Isochronal annealing resulted to a stronger recovery of radiation damage than implantation at elevated temperatures. However, the original glassy carbon structure was not achieved at the highest annealing temperature of $600{ }^{\circ} \mathrm{C}$. Implantation at higher temperatures resulted to some migration of implanted $\mathrm{Cd}$ more towards the surface. This migration was accompanied by significant loss of $\mathrm{Cd}$ at $600{ }^{\circ} \mathrm{C}$. Isochronal annealing caused migration of $\mathrm{Cd}$ in the less defective region at lower temperature and migration of Cd towards the surface at higher temperature. This was explained by trapping and detrapping of implanted Cd in GC.

\section{Acknowledgements}

Special thanks to National Research Foundation-South Africa for financial support. 


\section{References}

[1] S. S. Bukalov, L. a Leites, a I. Sorokin, and a S. Kotosonov, "Structural Changes in Industrial Glassy Carbon As a Function of Heat Treatment Temperature According To Raman Spectroscopy and X-Ray," Nanosyst. Physics, Chem. Math., vol. 5, no. 1, pp. 186-191, 2014.

[2] P. J. F. Harris, "Fullerene-related structure of commercial glassy carbons," Philos. Mag., vol. 84, no. 29, pp. 3159-3167, Oct. 2004.

[3] T. Noda, M. Inagaki, and S. Yamada, "A Comment on the Structure of Glassy Carbon," Bull. Chem. Soc. Jpn., vol. 41, no. 12, pp. 3023-3024, 1968.

[4] E. A. Taft and H. R. Philipp, "Optical Properties of Graphite," Phys. Rev. A, vol. 138, no. 1, pp. 197-199, 1965.

[5] V. Bernardet, S. Gomes, S. Delpeux, M. Dubois, K. Guérin, D. Avignant, G. Renaudin, and L. Duclaux, "Protection of nuclear graphite toward fluoride molten salt by glassy carbon deposit," J. Nucl. Mater., vol. 384, pp. 292-302, 2009.

[6] H. Kleykamp, "The chemical state of the fission products in oxide fuels," J. Nucl. Mater., vol. 131, pp. 221-246, 1985.

[7] M. Liu, Y. Feng, G. Wang, and B. Fang, "Determination of cadmium(II) using glassy carbon electrodes modified with cupferron, ??-naphthol, and multiwalled carbon nanotubes," Microchim. Acta, vol. 177, no. 1-2, pp. 221-228, 2012.

[8] O. Koskelo, U. Köster, I. Riihimäki, and J. Räisänen, "Migration kinetics of ionimplanted beryllium in glassy carbon," Diam. Relat. Mater., vol. 17, no. 12, pp. 1991-1993, 2008.

[9] D. F. Langa, N. G. Van Der Berg, E. Friedland, J. B. Malherbe, A. J. Botha, P. Chakraborty, E. Wendler, and W. Wesch, "Heat treatment of glassy carbon implanted with cesium at room and high temperatures," Nucl. Inst. Methods Phys. Res. B, vol. 273, pp. 68-71, 2012.

[10] O. S. Odutemowo, J. B. Malherbe, L. Prinsloo, D. F. Langa, and E. Wendler, "High temperature annealing studies of strontium ion implanted glassy carbon," Nucl. Instruments Methods Phys. Res. Sect. B Beam Interact. with Mater. Atoms, vol. 371, pp. 332-335, 2016.

[11] V. Lavrentiev, J. Vacik, and H. Naramoto, "Structural phenomena in glassy carbon induced by cobalt ion implantation," Appl. Phys. A Mater. Sci. Process., vol. 92, no. 3, pp. 673-680, 2008.

[12] A. Nakao, M. Iwaki, and Y. Yokoyama, "Potassium ion implantation into glassy carbon," Nucl. Instruments Methods Phys. Res. Sect. B Beam Interact. with Mater. Atoms, vol. 206, pp. 211-214, 2003.

[13] M. Iwaki and K. Terashima, "Change in atomic density of glassy carbon by Na ion implantation," pp. 429-433, 2000.

[14] S. Nakao, K. Saitoh, M. Ikeyama, H. Niwa, S. Tanemura, Y. Miyagawa, S. Miyagawa, P. Jin, T. Bell, L. . Wielunski, and M. . Swain, "Microindentation measurements of glassy carbon implanted with high-energy titanium ions," Surf. 
Coatings Technol., vol. 103-104, pp. 384-388, 1998.

[15] A. Hoffman, H. Geller, I. Gouzman, C. Cytermann, R. Brener, and M. Kenny, "Formation of carbon nitride films by high-energy nitrogen ion implantation into glassy carbon," Surf. Coatings Technol., vol. 68-69, pp. 616-620, 1994.

[16] D. McCulloch, A. Hoffman, P. J. Evans, and S. Prawer, "Structural and chemical bonding investigation of tungsten implanted glassy carbon," Nucl. Inst. Methods Phys. Res. B, vol. 80-81, no. PART 2, pp. 1460-1463, 1993.

[17] M. Iwaki, K. Takahashi, K. Yoshida, and Y. Okabe, "Improvement of wear properties of glassy carbon surface layer modified by ion implantations," Nucl. Inst. Methods Phys. Res. B, vol. 39, no. 1-4, pp. 700-703, 1989.

[18] L. C. Prinsloo and P. Colomban, "A Raman spectroscopic study of the Mapungubwe oblates : glass trade beads excavated at an Iron Age archaeological site in South Africa," no. October 2007, pp. 79-90, 2008.

[19] A. C. Ferrari and J. Robertson, "Interpretation of Raman spectra of disordered and amorphous carbon," Phys. Rev. B, vol. 61, no. 20, pp. 14095-14107, May 2000.

[20] D. G. McCulloch, S. Prawer, and A. Hoffman, "Structural investigation of xenonion-beam-irradiated glassy carbon," Phys. Rev. B, vol. 50, p. 5905, 1994.

[21] J. F. Ziegler, M. D. Ziegler, and J. P. Biersack, "SRIM - The stopping and range of ions in matter (2010)," Nucl. Instruments Methods Phys. Res. Sect. B Beam Interact. with Mater. Atoms, vol. 268, no. 11-12, pp. 1818-1823, Jun. 2010.

[22] S. M. Myers, S. T. Picraux, and T. S. Prevender, "Study of Cu diffusion in Be using ion backscattering," Phys. Rev. B, vol. 9, pp. 3953-3964, 1974. 